\title{
INFECÇÃO BACTERIANA NO PACIENTE CIRRÓTICO
}

\author{
Angelo A. de MATTOS, Gabriela P. CORAL, Eduardo MENTI, \\ Fabiana VALIATTI e Caroline KRAMER
}

RESUMO - Racional - Em torno de 30\% dos pacientes com cirrose hepática apresentam infecção bacteriana na admissão hospitalar ou a desenvolvem durante a mesma. As infecções bacterianas são responsáveis por até $25 \%$ das mortes nesta população de pacientes. Objetivo - Avaliar a prevalência de infecção bacteriana em uma população de pacientes cirróticos internados em hospital geral, bem como correlacionar sua presença com a etiologia alcoólica da hepatopatia, com o grau de comprometimento da função hepática e com a presença de hemorragia digestiva alta. Pacientes $\boldsymbol{e}$ métodos - Foram avaliadas retrospectivamente 541 internações hospitalares consecutivas em 426 pacientes com cirrose hepática, internados no período de 1992 a 2000 . A média de idade destes pacientes foi de 50,5 anos (15-95), sendo $71,2 \%$ do sexo masculino. Etiologia alcoólica da hepatopatia esteve presente em $35,4 \%$ dos pacientes. Alta ou óbito do paciente no período da internação hospitalar foi considerado como principal desfecho. O nível de significância considerado na análise estatística foi de 5\%. Resultados - As infecções bacterianas ocorreram em 25\% dos cirróticos (135 episódios). Destas, as mais freqüentes foram: a infecção do trato urinário em 31,1\%, a peritonite bacteriana espontânea em $25,9 \%$ e a broncopneumonia em $25,2 \%$. Ocorreu associação de infecção urinária e broncopneumonia em 3,7\% e infecção de pele e tecido celular subcutâneo em 11,11\%. Bacteremia sem foco definido ocorreu nos quatro casos restantes $(2,9 \%)$. Houve associação da presença de infecção com a etiologia alcoólica da hepatopatia, com a classificação de Child-Pugh e com a ocorrência de hemorragia digestiva alta. A mortalidade hospitalar foi maior nos pacientes infectados $(8,9 \%)$, estando a mesma associada ao grau de disfunção hepatocelular. Conclusões - A ocorrência de infecção bacteriana no paciente cirrótico hospitalizado é freqüente e correlaciona-se com a etiologia alcoólica da hepatopatia, com a reserva funcional hepática e com a presença de sangramento digestivo. Além disso, a presença de infecção bacteriana correlacionase com mau prognóstico.

DESCRITORES - Infecções bacterianas. Cirrose hepática. Hemorragia gastrointestinal.

\section{INTRODUÇÃO}

Os pacientes com cirrose hepática têm maior prevalência de infecção bacteriana, que determina pior prognóstico ${ }^{(6,15)}$. As infecções mais freqüentemente descritas nessa população de doentes são a infecção urinária, a pneumonia, a infecção de pele e tecido celular subcutâneo e a peritonite bacteriana espontânea $(\mathrm{PBE})^{(1,6,15)}$.

As causas desta maior susceptibilidade à infecção, especialmente neste grupo de pacientes, são várias: desde a capacidade diminuída do fígado cirrótico em remover as endotoxinas e bactérias, em decorrência da circulação colateral existente e da diminuição da atividade do sistema retículo endotelial, até estado de imunodepressão sistêmica e local representado pelas alterações de complemento, imunoglobulinas e atividade opsônica plasmática e do líquido de ascite ${ }^{(2,3,14,27)}$.

Estudos realizados no Brasil chamaram a atenção para a associação da infecção bacteriana com a etiologia alcoólica da hepatopatia ${ }^{(27)}$, com a classe C de Child-Pugh ${ }^{(6,27)}$ e com a ocorrência de hemorragia digestiva alta ${ }^{(1)}$. Embora esses estudos tenham analisado número importante de pacientes, nenhum deles no nosso meio, foi realizado incluindo casuística significativamente maior e avaliando os critérios acima em conjunto.

O objetivo do presente estudo foi avaliar a prevalência de infecção bacteriana em população de pacientes cirróticos internados em hospital geral, bem como determinar a correlação da infecção bacteriana com a etiologia alcoólica da hepatopatia, com o grau de falência hepática e com a presença de hemorragia digestiva alta.

Curso de Pós-Graduação em Medicina: Hepatologia da Fundação Faculdade Federal de Ciências Médicas de Porto Alegre / Irmandade Santa Casa de Misericórdia de Porto Alegre, Porto Alegre, RS.

Endereço para correspondência: Dr. Angelo A. Mattos. Rua Cel. Aurélio Bittencourt, 35-201 - 90430-080 - Porto Alegre, RS. e-mail: hmb@ santacasa.tche.br. 


\section{MATERIAL E MÉTODOS}

Foram avaliadas retrospectivamente 541 internações hospitalares consecutivas em 426 pacientes com cirrose hepática, internados no período de 1992 a 2000. A média de idade destes pacientes foi de 50,5 anos (15-95), sendo 71,2\% do sexo masculino.

O diagnóstico de cirrose foi estabelecido pelo resultado da biopsia hepática (26,5\%) e/ou por dados clínicos, ecográficos e endoscópicos compatíveis. Observou-se ascite em $54,7 \%$ dos casos.

A causa da hepatopatia era definida de acordo com os seguintes critérios: ingestão de álcool acima de $80 \mathrm{~g}$ por dia, por no mínimo 12 $\operatorname{anos}^{(20)}$, caracterizava etiologia alcoólica, presença de HBsAg e/ou anti-VHC, etiologia viral B e C, respectivamente, titulação do fator antinuclear e anticorpo antimúsculo liso superior a 1:40 sugeria hepatopatia de origem auto-imune; anticorpo antimitocôndria em nível superior a 1:40 era utilizado no diagnóstico de cirrose biliar primária. Níveis de ferritina (>150 ng/mL na mulher e $250 \mathrm{ng} / \mathrm{mL}$ no homem) e saturação de transferrina ( $>50 \%$ na mulher e $62 \%$ no homem) elevados, sugeriam hemocromatose ${ }^{(9)}$. Cobre sérico elevado, ceruloplasmina inferior a $20 \mathrm{mg} / \mathrm{dL}$ e anéis de Kayser-Fleischer eram considerados para o diagnóstico da doença de Wilson ${ }^{(30)}$. Valores reduzidos de alfa1-antitripsina eram considerados para o diagnóstico de deficiência desta enzima ${ }^{(21)}$. Foi sistematicamente pesquisado o uso de medicamentos considerados hepatotóxicos. Nos casos em que não foi preenchido nenhum dos critérios acima, a hepatopatia foi considerada criptogenética.

Utilizando os critérios especificados, em 150 pacientes a gênese da hepatopatia foi atribuída ao álcool $(35,4 \%)$, em 145, ao vírus da hepatite $\mathrm{C}(34,0 \%)$, em 92, ao álcool associado ao vírus da hepatite $\mathrm{C}$ $(21,6 \%)$ e em 21 , ao vírus da hepatite B $(5,0 \%)$. Outros diagnósticos foram responsáveis pelos seis casos restantes $(1,4 \%)$, sendo três por etiologia medicamentosa, um por cirrose biliar primária e dois por hepatite auto-imune. Em 12 casos (2,8\%) não foi possível o diagnóstico etiológico.

Os pacientes foram classificados quanto ao grau de disfunção hepática de acordo com a classificação de Child modificada por $\mathrm{Pugh}^{(23)}$. Só se obtiveram dados descritivos que permitissem utilizá-la com segurança em 470 casos. Destes, $24,9 \%$ pertenciam à classe $\mathrm{A}, 41,1 \%$ à classe $\mathrm{B}$ e $34,1 \%$ à classe $\mathrm{C}$.

As características da população avaliada podem ser observadas na Tabela 1.

O diagnóstico de PBE foi estabelecido quando a contagem de polimorfonucleares no líquido de ascite era superior a 250 células/ $\mathrm{mm}^{3}$, independentemente do resultado da cultura ${ }^{(26)}$. O diagnóstico de infecção urinária foi estabelecido na dependência de sintomas característicos, associados ao crescimento bacteriano em cultura de urina superior a 100.000 colônias/mL. Broncopneumonia foi diagnosticada através de dados clínicos, radiológicos e bacteriológicos compatíveis e o diagnóstico de infecção de pele e subcutâneo foi estabelecido na presença de edema e hiperemia em pele e/ou partes moles. Pacientes sem fonte aparente de infecção, mas com febre, leucocitose com desvio à esquerda, e/ou hemocultura positiva foram considerados como tendo bacteremia.

TABELA 1 - Características dos 426 pacientes avaliados

\begin{tabular}{lc}
\hline Característica & Valor \\
\hline Idade - anos & 50,5 \\
Sexo masculino - n $(\%)$ & $303(71,2)$ \\
Etiologia - n (\%) & \\
Álcool & $150(35,4)$ \\
VHC & $145(34,0)$ \\
álcool + VHC & $92(21,6)$ \\
VHB & $21(5,0)$ \\
criptogênica & $12(2,8)$ \\
outros & $6(1,4)$ \\
Classificação de Child-Pugh & \\
A & $106(24,9)$ \\
B & $174(41,1)$ \\
C & $146(34,1)$ \\
\hline
\end{tabular}

O diagnóstico de hemorragia digestiva alta foi estabelecido mediante exteriorização de sangramento (melena e/ou hematêmese) ou queda do hematócrito/hemoglobina associadas a achados endoscópicos compatíveis com sangramento ativo ou recente.

O desfecho considerado foi alta ou óbito do paciente no período da internação hospitalar.

O presente estudo foi aprovado pelo Comitê de Ética do hospital

Realizou-se análise descritiva dos dados e calculou-se a média e desvio-padrão para as variáveis quantitativas e percentual para as categóricas. Para avaliar a associação entre as variáveis categóricas foi realizado o teste do Qui-quadrado.

O nível de significância considerado para análise estatística foi 5\%.

\section{RESULTADOS}

Foram diagnosticados 135 episódios de infecção bacteriana nas 541 internações analisadas (25\%). A média de idade dos pacientes infectados foi de 46,5 anos (15-75), sendo $68,1 \%$ do sexo masculino. As infecções mais freqüentemente observadas foram a do trato urinário em 42 episódios $(31,1 \%)$, a PBE em 35 $(25,9 \%)$ e a broncopneumonia em 34 (25,2\%). Ocorreu associação de infecção urinária e broncopneumonia em cinco casos $(3,7 \%)$. Infecção de pele e tecido celular subcutâneo foi observada em 15 casos $(11,1 \%)$. Bacteremia sem foco definido ocorreu nos quatro casos restantes $(2,9 \%)$. 
Em relação à presença de infecção e sua associação com a etiologia da cirrose, observou-se maior freqüência da etiologia alcoólica nos pacientes infectados $(68,9 \%)$, quando comparada a outras causas de hepatopatia $(30,4 \%)(P=0,021)$. Por outro lado, os pacientes infectados eram predominantemente da classe Child-Pugh B ou $\mathrm{C}$ $(84,8 \%)$ quando comparados aos não-infectados $(72,1 \%)(P=0,006)$.

A hemorragia digestiva alta ocorreu em 35 casos da amostra $(6,5 \%)$, sendo que se observou infecção em 42,9\% dos episódios. Quando se avaliaram os pacientes sem sangramento, a infecção esteve presente em $23,7 \%$ dos casos. Houve diferença estatística em relação à freqüência de infecção entre estas duas populações $(P=0,011)$.

O percentual de óbitos na amostra geral de pacientes foi $4,3 \%$. Os óbitos foram mais freqüentes nos infectados $(8,9 \%)$, quando comparado aos não-infectados $(2,7 \%)(P=0,002)$.

Nos pacientes infectados, quando a etiologia da hepatopatia era decorrente do álcool, observou-se que a mortalidade $(9,6 \%)$ não diferiu significativamente daquela observada quando a gênese da mesma era decorrente de outras causas $(7,1 \%)(P=0,63)$.

Por outro lado, na análise da mortalidade dos pacientes infectados em relação ao grau de disfunção hepatocelular, observou-se que os óbitos destes ocorreram predominantemente nos pacientes pertencentes às classes B ou C de Child Pugh $(95,7 \%)$, quando comparados àqueles casos pertencentes à classe $\mathrm{A}(4,3 \%)(P=0,019)$.

\section{DISCUSSÃO}

A prevalência de infecções bacterianas nos pacientes com cirrose hepática varia, na literatura, de $33 \%$ a $57 \%$. No presente estudo a prevalência de infecção nos pacientes cirróticos hospitalizados foi de $25 \%$, pouco menor do que em alguns estudos brasileiros ${ }^{(1,6,27)}$.

A PBE, a infecção do trato urinário (ITU), a pneumonia e a infecção de pele e tecido celular subcutâneo são as infecções mais freqüentemente observadas nos pacientes com hepatopatia crônica ${ }^{(1,6,15,27)}$.

A PBE é a infecção mais freqüente em alguns estudos ${ }^{(1,6,27)}$, embora no presente seja a segunda em frequiência, responsável por $25,9 \%$ dos casos. O principal fator desencadeador do surgimento da PBE parece ser a quebra da barreira mucosa intestinal e o mecanismo proposto, a translocação bacteriana. Esta representa a passagem de bactérias não-patogênicas, que normalmente colonizam o trato gastrointestinal pela parede intestinal, infectando sítios distantes, como nódulos linfáticos mesentéricos, baço e fígado. Os três principais mecanismos para explicar a translocação bacteriana, presentes nos pacientes com cirrose, são: alteração da flora intestinal, alteração da permeabilidade da mucosa intestinal e a diminuição das defesas do hospedeiro ${ }^{(2,11,31)}$. Uma vez atingindo a circulação sangüínea, em decorrência da translocação bacteriana, poderá sobrevir quadro de PBE devido à incapacidade do fígado em remover as bactérias da corrente sangüínea, pois as anastomoses portossistêmicas, tanto intra, quanto extra-hepáticas, permitem que as bactérias realizem curtocircuito, fugindo à captação do sistema retículo-endotelial que, provavelmente, é o maior sítio de remoção de bactérias ${ }^{(8,10)}$. Assim, há tendência à perpetuação da bacteremia, oferecendo oportunidade aos microorganismos de causarem infecção metastática em sítios suscetíveis. Por outro lado, a infecção no líquido de ascite é possibilitada pela diminuição de sua capacidade em destruir as bactérias em decorrência do comprometimento da atividade bactericida e opsônica do mesmo ${ }^{(28,29)}$.

A ITU ocorre em até $54 \%$ dos pacientes com cirrose ${ }^{(32)}$, embora dois estudos ${ }^{(1,27)}$ demonstrem prevalência bem menor, em torno de $10 \%$. Na presente casuística a prevalência foi de $31,1 \%$. Postula-se que a alta incidência de ITU nos pacientes com cirrose, especialmente naqueles com ascite, esteja correlacionada a volume urinário residual e possível disfunção vesical, freqüentemente encontrada nesses pacientes ${ }^{(4)}$. Contudo, na maioria das vezes, essa infecção ocorre no hospital e pode estar favorecida por instrumentação da uretra (colocação de sonda urinária), que é freqüente nesses pacientes, seja para controle de diurese ou por perda do controle esfincteriano, secundários à encefalopatia portossistêmica ${ }^{(12)}$.

$\mathrm{Na}$ literatura, e também na presente série, a pneumonia está entre as três infecções mais freqüentes no paciente cirrótico. A prevalência aqui detectada de $25,2 \%$ está de acordo com os $20 \%$ descritos $^{(1,6,27)}$. Postula-se que esta freqüência aumentada possa estar relacionada à aspiração decorrente do sangramento gastrointestinal alto, à encefalopatia hepática e aos vários procedimentos diagnósticos e terapêuticos realizados secundariamente ${ }^{(22)}$. Por outro lado, estudo avaliando modelo de cirrose em ratos, analisou a resposta destes comparados com controles (sem cirrose), à indução de pneumonia por inoculação intratraqueal de Streptococcus pneumoniae. Nesse estudo, o clareamento pulmonar do pneumococo foi mais reduzido nos ratos com cirrose e ascite, justificando, assim, maior probabilidade do desenvolvimento de infecção respiratória ${ }^{(18)}$.

As infecções dermatológicas ocorrem em $2 \%$ a $11 \%$ dos pacientes cirróticos $^{(6,21)}$ e parecem estar relacionadas à infiltração da pele e do tecido celular subcutâneo, decorrentes da retenção de água ${ }^{(6)}$. Na casuística avaliada observou-se esta complicação em $11,1 \%$ dos casos.

No presente estudo, observou-se maior prevalência de infecção quando a etiologia da hepatopatia era relacionada com o álcool; este achado também foi observado no estudo de ROSA et al. ${ }^{(27)}$. Acredita-se que o álcool aumente a permeabilidade da mucosa intestinal e diminua a ação das células de $\operatorname{Kupffer}^{(16,34)}$, favorecendo assim a infecção. O papel do álcool como imunossupressor também não deve ser esquecido $^{(17)}$.

Por outro lado, o grau de comprometimento da função hepática correlaciona-se com a maior prevalência de infecção, fato constatado tanto na literatura ${ }^{(1,6,27)}$, quanto no estudo presente. Assim, observou-se que $84,8 \%$ dos pacientes com infecção eram Child B ou C. 
Esses achados, provavelmente, sejam decorrentes de maior imunodepressão observada nesta população de doentes.

Outra variável correlacionada a maior probabilidade de infecção é a ocorrência de hemorragia gastrointestinal. Estudos prospectivos têm demonstrado que as infecções bacterianas, na ausência de profilaxia, são documentadas em $22 \%$ dos pacientes nas primeiras 48 horas da admissão por hemorragia digestiva alta e que em 7 a 14 dias após o sangramento inicial, a incidência de infecção bacteriana alcance $35 \%$ a $66 \%{ }^{(5,13)}$. Isto pode ocorrer por aumento da translocação bacteriana e por depressão do sistema retículo endotelial secundário à hipovolemia $^{(25)}$. No presente estudo houve maior prevalência de infecção nos pacientes com hemorragia digestiva alta $(42,9 \%)$, sendo esta diferença estatisticamente significativa, quando comparada aos pacientes sem esta complicação. O estudo de ALMEIDA et al. ${ }^{(1)}$ também demonstrou diferença na prevalência de infecção entre pacientes com ou sem hemorragia digestiva, apesar de não ter alcançado significância estatística.

Tendo em vista a freqüência das infecções nos pacientes com hepatopatia crônica, é fundamental que estejamos atentos para o impacto que a mesma produz no prognóstico destes doentes. Assim, considera-se que as infecções são responsáveis por até $25 \%$ das mortes nesta população de pacientes ${ }^{(6,7,24)}$ tanto diretamente, quanto pela precipitação de encefalopatia portossistêmica ${ }^{(33)}$, hemorragia digestiva alta $^{(13)}$ ou insuficiência renal ${ }^{(19)}$. Na presente série, a mortalidade foi significativamente maior na presença de infecção, quando comparada aos casos que não cursaram com esta complicação. Semelhante ao descrito na literatura ${ }^{(1,27)}$, houve associação significativa entre o grau de disfunção hepática e a mortalidade; quase todos os pacientes infectados que morreram pertenciam à classe $\mathrm{B}$ ou $\mathrm{C}$ de Child-Pugh. Por outro lado, como já demonstrado em outro estudo $^{(27)}$, não houve correlação entre a mortalidade e a etiologia da hepatopatia.

Conclui-se que é freqüente o diagnóstico de infecção bacteriana no paciente cirrótico hospitalizado e que a mesma correlaciona-se com a etiologia alcoólica da hepatopatia, com a reserva funcional hepática e com a presença de sangramento digestivo. A mortalidade hospitalar é maior nos pacientes infectados, principalmente naqueles com pior função hepática.

Mattos AA, Coral GP, Menti E, Valiatti F, Kramer C. Bacterial infection in cirrhotic patients. Arq Gastroenterol 2003;40(1):11-15.

ABSTRACT - Background - Bacterial infections at admission or during hospitalization are frequent complication of cirrhosis that occurs in about $30 \%$ of the cases. Furthermore they are responsible for $25 \%$ of deaths in this population. Aim - Evaluate the prevalence of bacterial infections in cirrhotic patients at a general hospital and determine its correlation with alcoholic etiology of liver disease; degree of hepatic dysfunction and upper gastrointestinal bleeding. Patients/Methods - Five hundred and forty one admissions were retrospectively evaluated in 426 cirrhotic patients at years 1992 to 2000 . The mean age was 50.5 years (15-95), being 71.2\% male. The alcoholic etiology of cirrhosis was 35.4\%. The main outcome considered was discharge or death during admission. Results - One hundred and thirty five episodes of bacterial infections (25\%) were diagnosed. The most frequent are urinary tract infection $(31.1 \%)$, spontaneous bacterial peritonitis $(25.9 \%)$ and pneumonia $(25.2 \%)$. The association between urinary tract infection and pneumonia occurred in 3.7\% and erysipelas or cellulites in $11.1 \%$. Bacteremia occurred in $2.9 \%$. There was a correlation between bacterial infection and alcoholic etiology of liver disease, hepatic dysfunction and upper gastrointestinal bleeding. The mortality was higher in the infected patients $(8.9 \%)$ and in those with a poor hepatic function. Conclusions - Bacterial infections are common complications in cirrhotic patients and are correlated with alcoholic etiology, Child Pugh classification and upper gastrointestinal bleeding. Furthermore, bacterial infections are correlated with poor prognosis.

HEADINGS - Bacterial infections. Liver cirrhosis. Gastrointestinal hemorrhage.

\section{REFERÊNCIAS BIBLIOGRÁFICAS}

1. Almeida D, Lopes A, Santos-Jesus R, Peres I, Bittencourt H, Paraná R. Comparative study of bacterial infection prevalence between cirrhotic patients with and without upper gastrointestinal bleeding. Braz J Infect Dis 2001;5:136-41.

2. Almeida JFC, Mattos AA. Comportamento dos mecanismos de defesa imunológica em pacientes com hepatopatia crônica descompensada. Rev AMRIGS 1997;41:13-9.

3. Almeida JFC, Mattos AA. Proteínas de defesa do líquido de ascite nas hepatopatias crônicas. GED Gastroenterol Endosc Dig 1996;13:10-8

4. Bercoff E, Déchelotte P, Weber J, Morcamp D, Denis P, Bourreille J. Urinary tract infection in cirrhotic patients, a urodynamic explanation. Lancet 1985;1:1987.

5. Bernard B, Cadranel JF, Valla D, Escolano S, Jarlier V, Opolon P. Prognostic significance of bacterial infection in bleeding cirrhotic patients: a prospective study. Gastroenterology 1995;108:1828-34

6. Caly WR, Strauss E. A prospective study of bacterial infections in patients with cirrhosis. J Hepatol 1993; 18:353-8.

7. Clària J, Titos E, Jimenéz W, Ros J, Ginés P, Arroyo V, Rivera F, Rodés J. Altered biosynthesis of leukotrienes and lipoxins and host defense disordes in patients with cirrhosis and ascites. Gastroenterology 1998;115:147-56.
8. Correia JP, Conn HO. Spontaneous bacterial peritonitis in cirrhosis: endemic or epidemic? Med Clin North Am 1975;59:936-81.

9. Crawford DHG, Jazwinska EC, Cullen LM, Powell L. Expression of hemocromatosis in homozygous and heterozygous subjects diagnosed according to the $\mathrm{C} 282 \mathrm{Y}$ mutation: evaluation of diagnostic criteria. Gastroenterology 1988;114:1003-8.

10. Crossley IR, Willians R. Spontaneous bacterial peritonitis. Gut 1985;26:325-31.

11. Deitch EA, Winterton J, Li M, Berg R. The gut as a portal of entry for bacteremia. Role of protein malnutrition. Ann Surg 1987;205:681-92.

12. Gomez-Jimenez J, Vilardell F, Casair L. Infecciones urinarias del cirrhotico. Rev Esp Enferm Ap Dig 1979;9:321-6.

13. Goulis J, Armonis A, Patch D, Sabin C, Greenslade L, Burroughs AK. Bacteria infection is independently associated with failure to control bleeding in cirrhotic patients with gastrointestinal hemorrhage. Hepatology 1998;27:1207-12.

14. Guarner C, Runyon BA. Macrophage function in cirrhosis and the risk of bacteria infection. Hepatology 1995;22:367-9.

15. Ho H, Zuckerman MJ, Ho TK, Guerra LG, Verghese A, Casner PR. Prevalence of associated infections in community-acquired spontaneous bacterial peritonitis Am J Gastroenterol 1996;91:735-42.

16. Janarson I, Ward K, Peters TJ. The leaky gut of alcoholism: possible route of entry for toxin compounds. Lancet 1984;1:179-82. 
17. McCullough. Alcoholic liver disease. In: Schiff ER, Sorrel MF, Maddrey WC, editors. Disease of the liver. Philadelphia: Lippincott Raven; 1999. p.941-71.

18. Mellemcap MA, Preheim LC. Pneumococcal pneumonia in a rat model of cirrhosis: effect of cirrhosis on pulmonary defense mechanisms against Streptococcus pneumoniae. J Infect Dis 1991;163:102-8.

19. Navasa M, Follo A, Filella X, Jiménez W, Francitorra A, Planas R, Rimola A, Arroyo V, Rodés J. Tumor necrosis factor and interleukin-6 in spontaneous bacterial peritonitis in cirrhosis: relationship with the development of renal impairment and mortality. Hepatology 1998;27:1227-32.

20. Norton R, Batey R, Dwyer T, MacMahon S. Alcohol consumption and the risk of alcohol related cirrhosis in women. Br Med J (Clin Res Ed) 1987;295:80-2.

21. Perlmutter DH. Alpha 1 antitripsyn deficiency. In: Schiff ER, Sorrel MF, Maddrey WC, editors. Disease of the liver. Philadelphia: Lippincott Raven; 1999. p.1131-50.

22. Ponzromero F, Echeverrua VS. Infecciones bacterianas en el cirrotico. Gastroenterol Hepatol 1988;11:67-75.

23. Pugh RNH, Murray-Lyon IM, Dawson JL, Pietroni MC, Williams R. Transection of the oesophagus in bleeding oesophageal varices. Br J Surg 1973;60:648-52.

24. Rimola A, Soto R, Bory F, Arroyo V, Piere C, Rodes J. Reticuloendotelial system phagocytic activity in cirrhosis and its relation to bacterial infections and prognosis. Hepatology 1984;4:53-8.

25. Rimola A, Bory F, Teres J, Perez-Ayuso RM, Arroyo V, Rodes J. Oral, non absorbable antibiotics prevent infection in cirrhotics with gastrointestinal hemorrage. Hepatology 1985;5:463-7.

26. Rimola A, Garcia-Tsao G, Navasa M, Piddock L, Planas R, Bernard B, Inadomi J, IAC. Diagnosis, treatment and profilaxis of spontaneous bacterial peritonitis: a consensus document. J Hepatol 2000;32:142-53.
27. Rosa H, Silvério AO, Perini R, Arruda C. Bacterial infection in cirrhotic patients and its relationship with alcohol. Am J Gastroenterol 2000;95:1290-3.

28. Runyon BA, Morrissey RL, Hoefs JC, Wyle FA. Opsonic activity of human ascitic fluid: a potentially important protective mechanism against spontaneous bacterial peritonitis. Hepatology 1985;5:634-7.

29. Runyon BA. Patients with deficient ascitic fluid opsonic activity are predisposed to spontaneous bacterial peritonitis. Hepatology 1998;8:632-5.

30. Schilsk ML, Tavill AS. Wilson's disease. In: Schiff ER, Sorrel MF, Maddrey WC, editors. Disease of the liver. Philadelphia: Lippincott Raven; 1999. p.1091-106.

31. Sorrel WT, Quigley EMM, Jin G, Johnson TJ, Rikkers LF. Bacterial translocation in the portal-hypertensive rat: studies in basal conditions and on exposure to hemorrhagic shock. Gastroenterology 1993;104:1722-6.

32. Stassen WN, McCullough AJ. Management of ascitis. Sem Liver Dis 1985;5:291 307.

33. Strauss E, Costa MF. The importance of bacterial infections as precipating factors of chronic hepatic encephalopathy in cirrhosis. Hepatogastroenterology 1998;5:900-4.

34. Winwood PJ, Arthur MJP. Kupffer cells: their activation and role in animals models of liver injury and human liver disease. Sem Liver Dis 1993;13:50-9.

Recebido em 10/4/2002 Aprovado em 22/8/2002. 